\title{
A New Copper(I) Complex Based on 4-amino-3,5-bis(3-pyridyl)-1,2,4-triazole: Synthesis, Crystal Structure, Theoretical Study, Thermal Behavior and Luminescence
}

\author{
CHEN AI-HUA $^{\mathrm{a}, *}$, MENG SU-CI ${ }^{\mathrm{b}}, \mathrm{ZHOU}^{\mathrm{K}} \mathrm{KI}^{\mathrm{a}}$, WANG CONG-CONG ${ }^{\mathrm{a}}, \mathrm{ZHAO} \mathrm{WEI}^{\mathrm{b}}$, \\ WANG AI-JIAN ${ }^{\mathrm{b}}$ and QIAN JUN ${ }^{\mathrm{b}}$ \\ ${ }^{a}$ School of Chemistry \& Chemical Engineering, Yancheng Institute of Technology, Yancheng 224051, \\ People's Republic of China \\ ${ }^{\mathrm{b}}$ School of Chemistry and Chemical Engineering, Jiangsu University, Zhenjiang 212013, \\ People's Republic of China \\ Email: chenaihuaycit@163.com; mengsc@ujs.edu.cn
}

MS received 8 November 2016; revised 16 December 2016; accepted 26 December 2016

\begin{abstract}
The synthesis, characterization and structure of a $1 \mathrm{D}$ coordination polymer $\{[\mathrm{CuBr}(3-\mathrm{abpt})] \cdot 2 \mathrm{DMSO}\}_{\mathrm{n}}$ (1) (3-abpt $=4$-amino-3,5-bis(3-pyridyl)-1,2,4-triazole) is described. X-ray structural analyses reveal that $\mathbf{1}$ exhibits a 1D ladder-like chain structure and each copper(I) center in $\mathbf{1}$ displays a distorted tetrahedral coordination geometry $\left\{\mathrm{CuN}_{3} \mathrm{Br}\right\}$. Density functional theory and time-dependent density functional theory calculations at the B3LYP/LanL2DZf+6-31G* level were performed on complex 1 to rationalize its experimental absorption spectra. The luminescent property and thermal behavior of the complex were also investigated.
\end{abstract}

Keywords. Copper(I) complex; crystal structure; dft calculations; luminescence.

\section{Introduction}

In recent years, the design and synthesis of organicinorganic hybrid complexes are of continuous interest not only for their various structural topologies ${ }^{1-3}$ but also for their potential applications in catalysis, biology and material science. ${ }^{4-8}$ As an important type of organic-inorganic hybrid complexes, copper(I) complexes based on copper halides and organic $\mathrm{N}$-donor ligands have drawn much attention due to their intriguing photophysical properties and possible utilization in light-emitting devices, electroluminescence devices, and probes of biological systems. ${ }^{9-14}$ The copper(I) ion has $\mathrm{d}^{10}$ electronic configuration and can adopt diverse coordination numbers. ${ }^{15,16}$ Also, the associated counter anion $\mathrm{X}(\mathrm{X}=\mathrm{Cl}, \mathrm{Br}, \mathrm{I})$ can be incorporated as an essential element of the framework. ${ }^{17,18}$ Organic N-donor ligands, particularly in the form of $\mathrm{N}$-heterocycles, have been widely used in metal coordination complexes due to their rich coordination mode. ${ }^{19-21}$ In particular, there is a growing interest in the development of crystal materials by using triazole ligands because of their rich coordination modes and interesting

*For correspondence properties. ${ }^{22-24}$ 4-Amino-3,5-bis(3-pyridyl)-1,2,4-triazole (3-abpt) is a rigid angular multifunctional ligand containing five potential $\mathrm{N}$-donors, which can serve as monodentate, bidentate and multidentate ligand. ${ }^{25-27}$ It has been found that many coordination complexes based on 3-abpt have novel architectures, interesting electrical and magnetic properties, and/or nonlinear optical properties. ${ }^{28-30}$ Accordingly, we have synthesized one new tetrahedrally coordinated copper(I) complex with 3-abpt and $\mathrm{CuBr}$, which displays a 1D ladderlike chain structure. The luminescence property and thermal behavior of this copper(I) complex were also investigated. Density functional theory (DFT) and time-dependent density functional theory (TD-DFT) calculations have afforded further insight into the electronic transitions and spectral characterization of this luminous copper(I) complex.

\section{Experimental}

\subsection{Materials and physical measurements}

All chemicals and solvents used for the syntheses were reagent grade and used without further purification. The 3abpt ligand was prepared according to literature methods. ${ }^{31}$ 
Elemental analyses for $\mathrm{C}, \mathrm{H}$, and $\mathrm{N}$ were performed on a Perkin-Elmer 240C system. Infrared spectra were recorded in the region $400-4000 \mathrm{~cm}^{-1}$ on a Nicolet Nexus $470 \mathrm{spec}-$ trometer (Germany) with samples as $\mathrm{KBr}$ disks. The UV-Vis absorption spectra were obtained with a FLASH EA 1112 spectrophotometer. Steady-state fluorescence spectra were measured on a Fluoro-Max-P instrument; samples were dissolved in dry ethanol, filtered, transferred to a long quartz cell, and then capped and deoxygenated by bubbling with $\mathrm{N}_{2}$ before measurement. Thermogravimetric analysis (TGA) measurements were carried out on a Perkin-Elmer Pyris 1 system under $\mathrm{N}_{2}$ purge with a heating rate of $10^{\circ} \mathrm{C} / \mathrm{min}$.

\subsection{Synthesis of complex 1}

Complex 1 was prepared by following a general synthetic procedure in which $\mathrm{CuBr}(0.014 \mathrm{~g}, 0.1 \mathrm{mmol})$ was added to $3 \mathrm{~mL}$ dimethyl sulfoxide (DMSO) and the resultant solution was stirred at room temperature for $0.5 \mathrm{~h}$. After filtration, 1 $\mathrm{mL}$ DMSO as the buffer was carefully layered onto the filtrate. $4 \mathrm{~mL} \mathrm{CH}{ }_{3} \mathrm{OH}$ containing 3-abpt $(0.0238 \mathrm{~g}, 0.1 \mathrm{mmol})$ was then very carefully layered on the top of the buffer solution. Yellow block crystals of complex 1 (0.0352 g) were obtained after several days (yield 65.6\%). Analysis calculated for $\mathrm{C}_{16} \mathrm{H}_{22} \mathrm{CuBrO}_{2} \mathrm{~S}_{2} \mathrm{~N}_{6}$ : C 35.72, $\mathrm{H}$ 4.12, N 15.62\%; found: $\mathrm{C} 35.68, \mathrm{H} 4.15, \mathrm{~N} 15.65 \%$. IR for 1 ( $\mathrm{KBr}$ pellets, $\left.\mathrm{cm}^{-1}\right)$ : $3439.2(\mathrm{~m}), 3239.2(\mathrm{~s}), 3088.8(\mathrm{~m}), 1615.6(\mathrm{w})$, $1463.3(\mathrm{~m}), 1390.7(\mathrm{~m}), 812.2(\mathrm{w}), 700.5(\mathrm{~m})$.

\section{$2.3 X$-ray data collection and structure refinement}

Single crystal X-ray diffraction data for complex 1 at $293 \mathrm{~K}$ were collected with the use of graphite-monochromated Mo- $K \alpha$ radiation $(\lambda=0.71073 \AA$ ) on a Rigaku Saturn $724^{+}$CCD diffractometer. A well-selected $0.22 \times 0.20 \times$ $0.18 \mathrm{~mm}^{3}$ yellow block crystal was used for the single crystal X-ray diffraction experiments. The SMART and SAINT program packages were used for data collection and integration, respectively. The collected data were also corrected for absorption using equivalent reflections and SADABS based upon Laue symmetry. The structure was solved by direct methods and refined on $F^{2}$ by the full-matrix leastsquares calculations with the use of SHELX-97 program package. ${ }^{32-34}$ All the non-hydrogen atoms were refined with anisotropic thermal displacement coefficients. All the hydrogen atoms were placed at the calculated positions and refined following the riding model. Details of the crystal parameters, data collection and refinement of complex $\mathbf{1}$ are summarized in Table 1.

\subsection{Density Functional Theoretical Study}

Density functional theory (DFT) and time-dependent density functional theoretical (TD-DFT) calculations were performed to rationalize the experimental absorption spectra by using the Gaussian 09 program. ${ }^{35}$ The model compound of complex $\mathbf{1}$ was selected from experimental X-ray

Table 1. Crystal and refinement data for $\mathbf{1}$.

\begin{tabular}{|c|c|}
\hline Formula & $\mathrm{C}_{16} \mathrm{H}_{22} \mathrm{CuBrN}_{6} \mathrm{O}_{2} \mathrm{~S}_{2}$ \\
\hline Formula weight & 537.96 \\
\hline Temperature /K & 293(2) \\
\hline Wavelength /Å & 0.71073 \\
\hline Crystal system & Monoclinic \\
\hline Space group & $P 2_{1} / c$ \\
\hline$a / \AA ̊$ & $12.444(3)$ \\
\hline$b / \AA$ & $12.647(3)$ \\
\hline$c / \AA ̊$ & $16.395(6)$ \\
\hline$\alpha /^{\circ}$ & 9.00 \\
\hline$\beta /^{\circ}$ & $124.47(2)$ \\
\hline$\gamma /{ }^{\circ}$ & 90.00 \\
\hline$V / \AA^{3}$ & 2127.2(11) \\
\hline Z & 4 \\
\hline$\rho_{\text {calcd. }} / g \bullet \mathrm{cm}^{-3}$ & 1.661 \\
\hline$F(000)$ & 1064 \\
\hline Limiting indices & $\begin{array}{l}-15 \leq h \leq 14,-13 \leq k \leq 15 \\
-17 \leq l \leq 20\end{array}$ \\
\hline Reflections collected & $989 \overline{3}--1+2$ \\
\hline Independent reflections & 4145 \\
\hline Independent reflections with $I>2 \sigma(I)$ & 3547 \\
\hline$R_{\text {int }}$ & 0.021 \\
\hline Completeness to $\Theta=26.03$ & $98.7 \%$ \\
\hline$\mu\left(\mathrm{mm}^{-1}\right)$ & 3.125 \\
\hline Refinement method & full-matrix least-squares on $F^{2}$ \\
\hline Goodness-of-fit on $F^{2}$ & 1.061 \\
\hline Final $R$ indices $[I>2 \sigma(I)]$ & $R_{1}=0.0627, w R_{2}=0.1490$ \\
\hline Rindices (all data) & $R_{1}=0.0534, w R_{2}=0.1410$ \\
\hline
\end{tabular}


single-crystal structure. The restricted singlet wave function for complex 1 in DMF (dielectric constant, $\varepsilon=36.71$ ) solution was tested to be stable with the framework of the polarized continuum model (PCM) using B3LYP functional. ${ }^{36,37}$ Here, the basis set $6-31 G^{*}+$ LanL2DZ* (using 6-31G* basis set for $\mathrm{C}, \mathrm{N}, \mathrm{Br}$, and $\mathrm{H}$ atoms, adding the f-type polarization functions to $\mathrm{Cu}$ atom at the basis set LanL2DZ) was employed in view of the influence of $d$ and $f$ functions on the absorption spectra. The exponent of $\mathrm{f}$ orbital for $\mathrm{Cu}$ (3.525) atom was selected as those in previous work. ${ }^{38}$ The vertical electronic excitation energies of complex 1 in DMF solution were then obtained through TD-DFT/PCM calculation at the same level.

\section{Results and Discussion}

\subsection{Crystal structure description}

$\mathrm{X}$-ray structural analysis reveals that the new copper(I) complex $\{[\mathrm{CuBr}(3-\mathrm{abpt})] \cdot 2 \mathrm{DMSO}\} \mathrm{n}(\mathbf{1})$ crystallizes in the monoclinic system with $P 21 / c$ space group. The coordination environment of $\mathrm{Cu}$ and the line drawing of $\mathbf{1}$ are depicted in Figure 1 and Figure S1 (in Supplementary

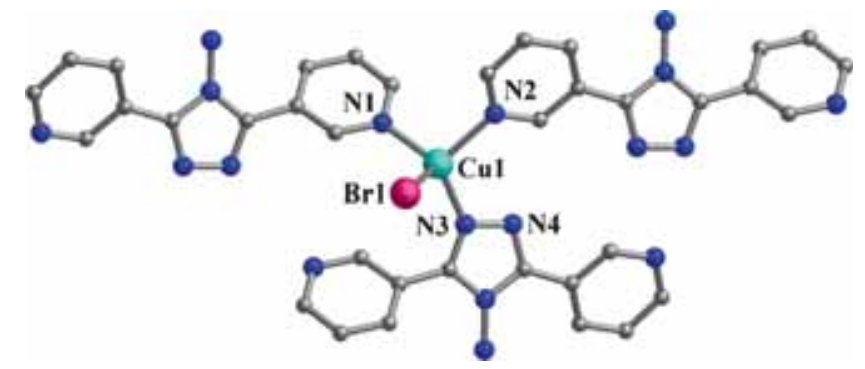

Figure 1. The coordination environment of $\mathrm{Cu}$ in complex 1. (The DMSO molecule and hydrogen atoms are omitted for clarity)
Information). Selected bond lengths ( $\mathrm{A})$ and angles $\left(^{\circ}\right)$ of $\mathbf{1}$ are listed in Table 2.

As shown in Figure 1, $\mathrm{Cu}$ atom is coordinated by one bromide ion, one triazole and two pyridyl nitrogen atoms from three different 3-abpt ligands, displaying a distorted tetrahedral coordination geometry $\left\{\mathrm{CuN}_{3} \mathrm{Br}\right\}$. The $\mathrm{Cu}-\mathrm{Br}(2.5105(1) \AA$ ) and $\mathrm{Cu}-\mathrm{N}$ bond lengths (2.010(4)-2.095(4) §) follow in the typical ranges. ${ }^{39,40}$ The bond angles around the $\mathrm{Cu}$ atom vary from $103.33(1)$ to $123.12(2)^{\circ}$. The 3 -abpt ligand exhibits a $\mu_{3}$-bridging mode, as a tridentate ligand coordinated to three copper(I) ions through triazole N3 and two pyridyl $\mathrm{N}$ donors. The triazole $\mathrm{N} 4$ and amino group are uncoordinated. The $\mathrm{Cu} 1$ and $\mathrm{Cu} 1 \mathrm{~A}$ are connected by two 3-abpt ligands to form a 12-membered ring (Figure 2). The 3-abpt ligand takes the cis-fashion to connect the two $\mathrm{Cu}$ atoms with a $\mathrm{Cu}$... Cu distance of 5.464(1) $\AA$. The dihedral angle between the $\mathrm{C} 1-\mathrm{N} 1$ and $\mathrm{C} 4-\mathrm{N} 2$ planes in the 3 -abpt ligand is $70.95^{\circ}$, showing some distortion.

The 12-membered ring units in complex $\mathbf{1}$ are bridged by pyridyl of 3-abpt ligands resulting in the formation of a one-dimensional ladder-like chain structure polymer as shown in Figure 3.

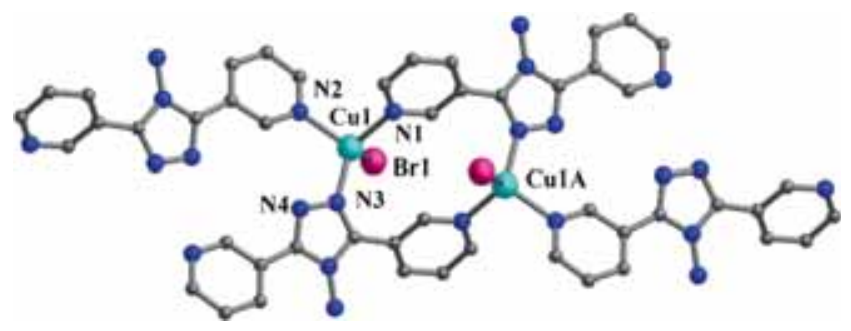

Figure 2. The ring structure in complex 1. (The DMSO molecule and hydrogen atoms are omitted for clarity)

Table 2. Selected bond lengths $(\AA)$ and angles $\left({ }^{\circ}\right)$ of $\mathbf{1}$.

\begin{tabular}{llll}
\hline Bond lengths $(\AA)$ & \multicolumn{3}{c}{ Bond lengths $(\AA)$} \\
\hline $\mathrm{Cu}(1)-\mathrm{N}(1)$ & $2.040(4)$ & $\mathrm{Cu}(1)-\mathrm{N}(2)$ & $2.095(4)$ \\
$\mathrm{Cu}(1)-\mathrm{N}(3)$ & $2.010(4)$ & $\mathrm{Cu}(1)-\mathrm{Br}(1)$ & $2.5105(1)$ \\
$\mathrm{C}(1)-\mathrm{C}(7) \# 1$ & $1.383(6)$ & $\mathrm{C}(3)-\mathrm{C}(6) \# 1$ & $1.383(7)$ \\
$\mathrm{C}(4)-\mathrm{C}(12) \# 2$ & $1.379(7)$ & $\mathrm{C}(5)-\mathrm{C}(10) \# 2$ & $1.388(7)$ \\
$\mathrm{B}$ nd angles $(\circ)$ & & $\mathrm{B}$ (ond angles $(\mathrm{\circ})$ & \\
$\mathrm{N}(1)-\mathrm{Cu}(1)-\mathrm{N}(2)$ & $104.60(2)$ & $\mathrm{N}(1)-\mathrm{Cu}(1)-\mathrm{N}(3)$ & $123.12(2)$ \\
$\mathrm{N}(2)-\mathrm{Cu}(1)-\mathrm{N}(3)$ & $109.54(2)$ & $\mathrm{N}(1)-\mathrm{Cu}(1)-\mathrm{Br}(1)$ & $103.33(1)$ \\
$\mathrm{N}(2)-\mathrm{Cu}(1)-\mathrm{Br}(1)$ & $109.44(1)$ & $\mathrm{N}(3)-\mathrm{Cu}(1)-\mathrm{Br}(1)$ & $106.23(1)$ \\
$\mathrm{C}(1)-\mathrm{N}(1)-\mathrm{Cu}(1)$ & $122.2(3)$ & $\mathrm{C}(2)-\mathrm{N}(1)-\mathrm{Cu}(1)$ & $121.0(3)$ \\
$\mathrm{C}(4)-\mathrm{N}(2)-\mathrm{Cu}(1)$ & $121.0(3)$ & $\mathrm{C}(5)-\mathrm{N}(2)-\mathrm{Cu}(1)$ & $122.3(3)$ \\
$\mathrm{C}(8)-\mathrm{N}(3)-\mathrm{Cu}(1)$ & $131.1(3)$ & $\mathrm{N}(4)-\mathrm{N}(3)-\mathrm{Cu}(1)$ & $120.4(3)$ \\
$\mathrm{N}(1)-\mathrm{C}(1)-\mathrm{C}(7) \# 1$ & $123.0(4)$ & $\mathrm{C}(2)-\mathrm{C}(3)-\mathrm{C}(6) \# 1$ & $119.7(4)$ \\
$\mathrm{N}(2)-\mathrm{C}(5)-\mathrm{C}(10) \# 2$ & $123.5(4)$ & $\mathrm{C}(5) \# 2-\mathrm{C}(10)-\mathrm{C}(11)$ & $118.5(4)$ \\
\end{tabular}

Symmetry transformation: \#1 : $-\mathrm{x}+2,-\mathrm{y},-\mathrm{z} ; \# 2-\mathrm{x}+1,-\mathrm{y},-\mathrm{z}$ 


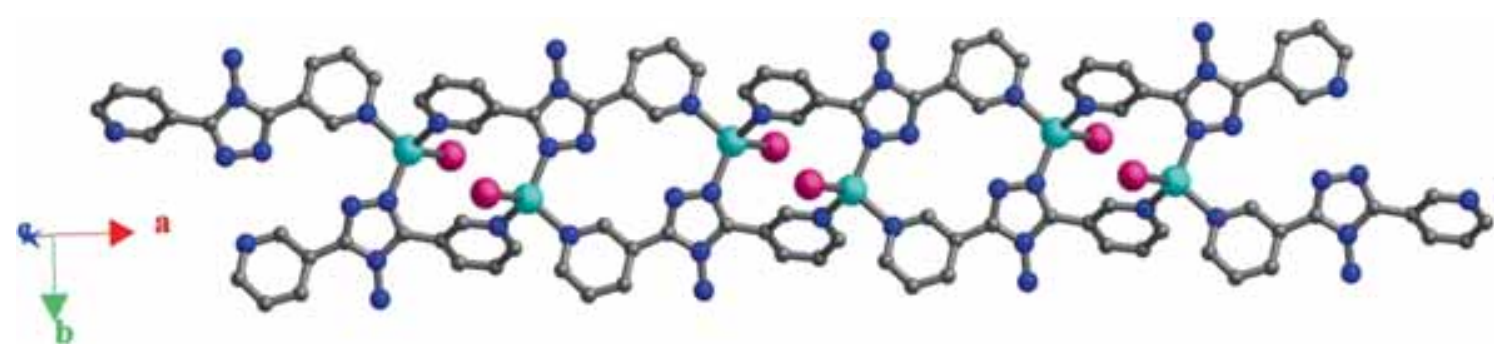

Figure 3. Packing diagram, a view down $c$-axis for complex 1. (The DMSO molecule and hydrogen atoms are omitted for clarity)

\subsection{Infrared Spectroscopy}

The complex 1 was stable at room temperature and possessed good keeping qualities. IR spectrum of complex $\mathbf{1}$ is shown in Figure S2 (Supplementary Information). For complex 1, the $v(\mathrm{C}-\mathrm{H})$ vibration of aromatic ring is observed at about $3089 \mathrm{~cm}^{-1}$. The peaks at 3439 and $3239 \mathrm{~cm}^{-1}$ may be attributed to the vibrations of the amino group of 3-abpt. Peaks appearing at 1616, 1463 and $1390 \mathrm{~cm}^{-1}$ should be assigned to stretching vibrations of the $\mathrm{C}=\mathrm{N} / \mathrm{C}=\mathrm{C}$ bonds in $\mathbf{1}$. The IR bands near 812 and $701 \mathrm{~cm}^{-1}$ belong to $v(\mathrm{C}-\mathrm{H})$ vibrations of the coordinated 3-abpt.

\subsection{Experimental and Theoretical Absorption Spectra}

To gain deeper insight into the electronic transitions and spectral characterization of this copper(I) complex, the TD-DFT/PCM calculations were performed for $\mathbf{1}$. The experimental absorption spectra of $\mathbf{1}$ were

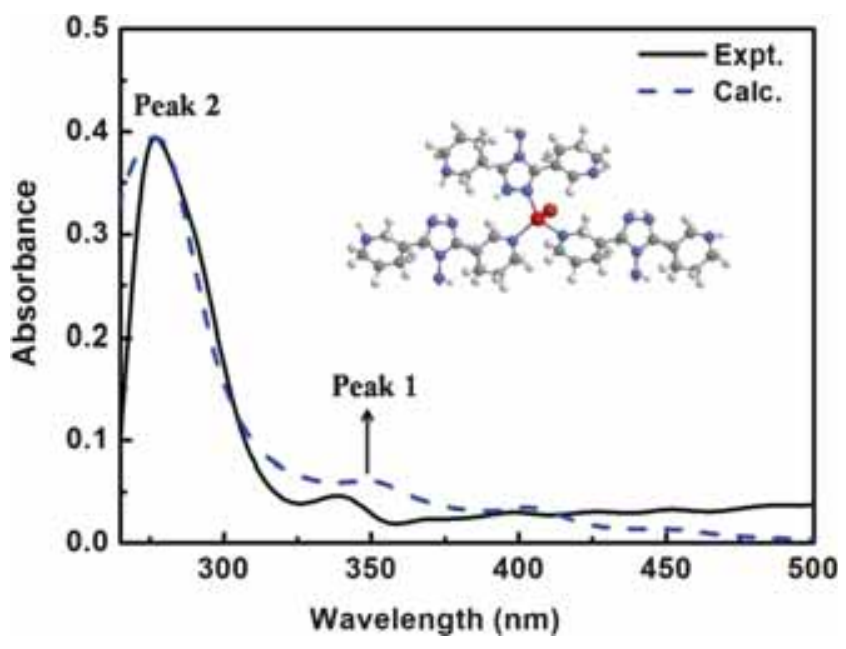

Figure 4. Absorption spectra of complex 1 obtained from experiment (black line) and TD-DFT/PCM calculations (blue dashed line) at the B3LYP/6-31G*+LanL2DZ* level. For the latter, a Lorentzian function has been adopted with the spectral linewidth set to be $70 \mathrm{~nm}$. The theoretical spectrum was shifted right by $12 \mathrm{~nm}$ from the TD-DFT/PCM excitation energies, respectively. measured in a $2.25 \times 10^{-5} \mathrm{~mol} \mathrm{dm}{ }^{-3}$ DMF solution. Figure 4 makes a comparison between the scaled absorption spectra of complex $\mathbf{1}$ with the Lorentzian function $^{41}$ and the experimental results, displaying a qualitative agreement in the shape of the absorption spectra. The lowest dipole-allowed absorption bands (peak 1) and the relatively stronger absorption bands (peak 2) of complex 1 are mainly assigned to the $\pi \rightarrow \pi^{*}$ transitions. As schematically illustrated in Figure 5, the lowest dipole-allowed absorption band of complex $\mathbf{1}$ is mainly ascribed to metal to ligand charge transfer. And the strongest absorption band of complex 1 involves ligand-ligand charge transfer.

\subsection{Thermogravimetric Analysis (TGA)}

To examine thermal stabilities of the complex $\mathbf{1}$, thermogravimetric analyses (TGA) were carried out between 20 and $800^{\circ} \mathrm{C}$ in flowing nitrogen at $10^{\circ} \mathrm{C} \cdot \mathrm{min}^{-1}$. As depicted in Figure 6, complex 1 shows a weight loss of $\sim 28.54 \%$ from 250 to $400^{\circ} \mathrm{C}$, corresponding to the loss of DMSO molecules (expected $=$ $29.04 \%$ ). The second weight loss of $\sim 44.25 \%$ occurs in the range $430-740^{\circ} \mathrm{C}$, which can be attributed to the release of 3-abpt ligand (calcd 44.28\%). In summary, the thermogravimetric analyses show that the complex 1 has reasonable thermal stability.

\subsection{Luminescence Behavior}

It is well-known that metal-organic coordination complexes constructed from central $\mathrm{d}^{10}$ metal atoms and organic ligands possess varied luminescent properties. ${ }^{42,43}$ Organic ligands and their coordinate modes obviously affect their emission wavelengths and luminescent mechanisms. ${ }^{44,45}$ In order to examine the fluorescent property of this $\mathrm{d}^{10}$ transition metal complex, the fluorescence spectra of complex 1 in ethanol solution was measured. As shown in Figure 7, the complex 1 shows a broad emission band in the blue region (maximal emission peak at $550 \mathrm{~nm}$ ) for excitation at $\lambda_{\text {ex }}=370 \mathrm{~nm}$. To understand more thoroughly the 

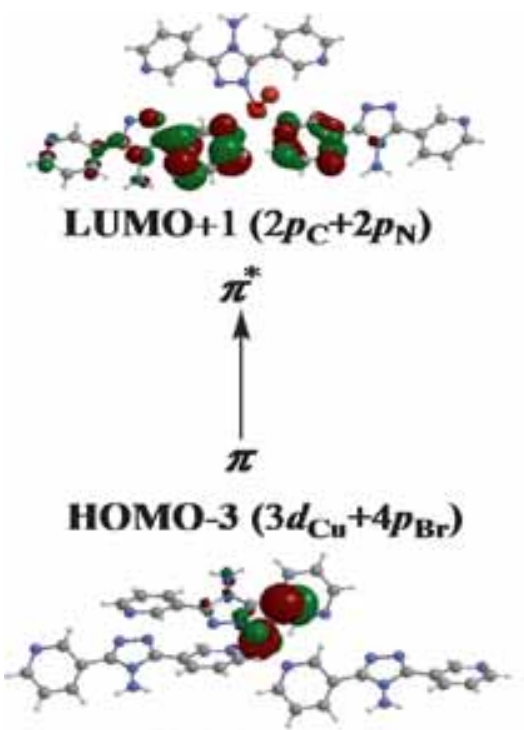

Peak 1

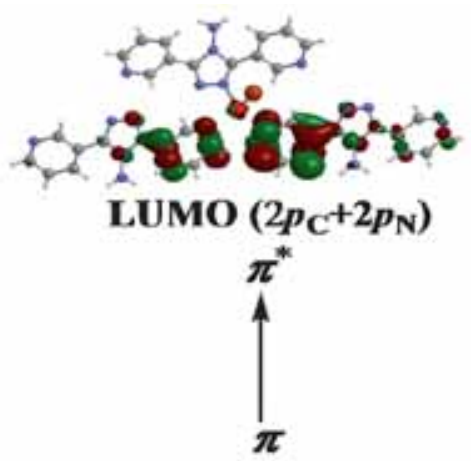

HOMO-10 $\left(2 p_{\mathrm{C}}+2 p_{\mathrm{N}}\right)$

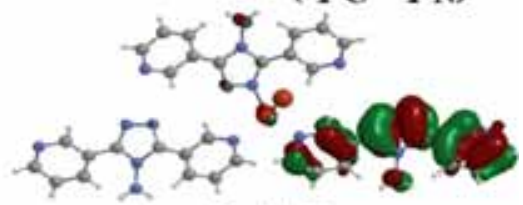

Peak 2

Figure 5. Assignment to absorption peaks of complex 1. The molecular orbitals were obtained through DFT/PCM calculations at the B3LYP/6$31 \mathrm{G}^{*}+\mathrm{LanL} 2 \mathrm{DZ} *$ level.

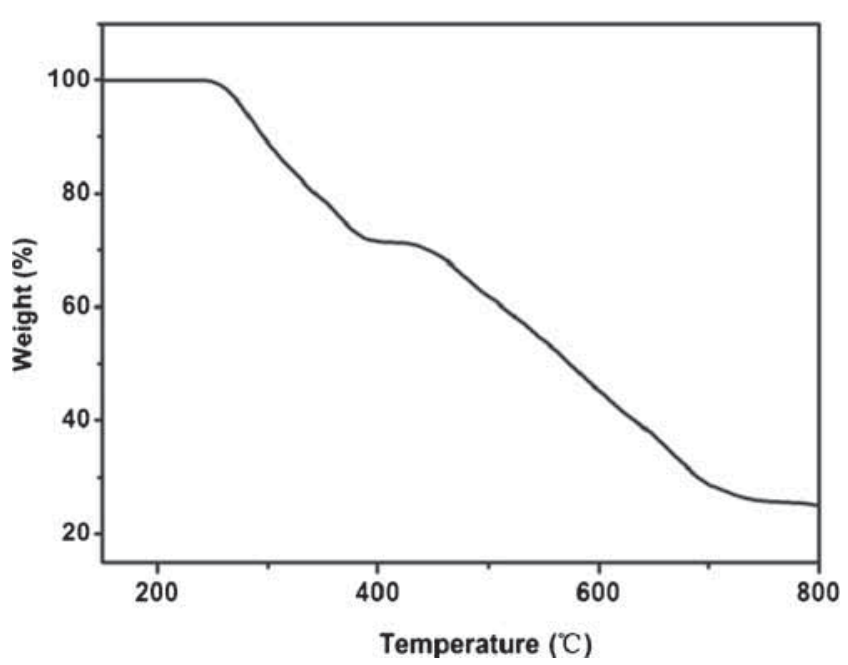

Figure 6. TGA curve of complex 1.

nature of this emission band, the luminescence of 3abpt ligand was also investigated in $\mathrm{EtOH}$ solution at room temperature. The free 3 -abpt ligand exhibits maximum emission at $418 \mathrm{~nm}$ upon excitation at $330 \mathrm{~nm}$, which may be attributed to the $\pi-\pi^{*}$ transition. By comparing the profiles and locations of the emission peaks of complex 1 with the corresponding free 3-abpt ligand, we can see a significant shift in the emission wavelength for the bound ligand, which probably comes from intra-ligand $\pi-\pi *$ transitions and metal-to-ligand charge transfer (MLCT) transitions. ${ }^{46,47}$ The red-shift of the peak in $\mathbf{1}$ is presumably a result of coordination of the relevant ligand to the metal atom. ${ }^{48}$ These

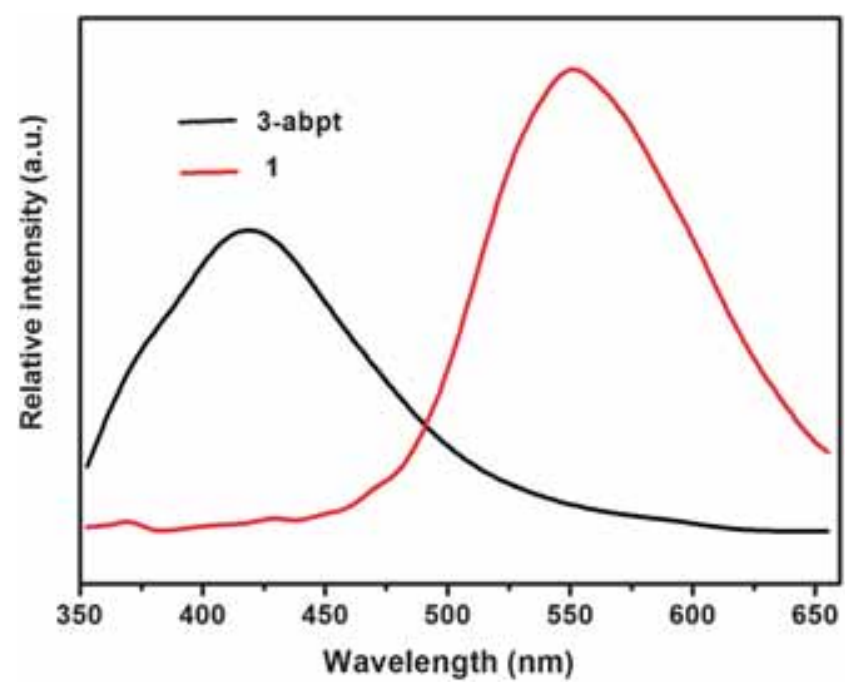

Figure 7. Fluorescence spectra of $3.0 \times 10^{-5} \mathrm{M}$ solutions of 1 and 3-abpt in ethanol at room temperature. Excitation wavelengths (nm): 370 (1), 330 (3-abpt).

results indicate that such metal complexes could be good candidates for photoactive materials.

\section{Conclusions}

In summary, a luminous copper(I) complex based on 4-amino-3,5-bis(3-pyridyl)-1,2,4-triazole (3-abpt) has been successfully prepared by slow diffusion method. $\mathrm{X}$-ray single crystal analysis reveals that the central portion of complex 1 consists of a 12-membered ring core and displays an infinite ladder-like chain structure. The 
theoretical absorption spectra of complex 1 obtained from DFT and TD-DFT calculations are in good agreement with the experimental spectrum. The intense fluorescent property of the title complex suggests that it may be used in the field of photoluminescent materials.

\section{Supplementary Information (SI)}

Crystallographic data (excluding structure factors) for the structure in this paper have been deposited with the Cambridge Crystallographic Data Centre, CCDC, 12 Union Road, Cambridge CB21EZ, UK. Copies of the data can be obtained free of charge on quoting the depository number CCDC-1506863 (Fax: +44-1223-336-033; E-Mail: deposit@ccdc.cam.ac.uk, http://www.ccdc.cam.ac.uk). The line drawing of complex 1 (Figure S1), FT-IR spectrum of complex 1 (Figure S2) and check cif file are given in Supplementary Information, which are available at www.ias.ac.in/ chemsci.

\section{Acknowledgements}

This research was supported financially by Natural Science Foundation of Jiangsu High School (15KJD150002, 15KJB430007, 15KJB610003, 16KJD430002) and National Natural Science Foundation of China (21103073, 51506077, 51602130), the Natural Science Foundation of Jiangsu Province (BK20150488), and the China Postdoctoral Foundation (2016M601733).

\section{References}

1. Li J R, Ma Y, McCarthy M C, Sculley J, Yu J, Jeong H K, Balbuena P B and Zhou H C 2011 Carbon dioxide capture-related gas adsorption and separation in metalorganic frameworks Coordin. Chem. Rev. 2551791

2. Dipu S, Habibar C, Sushovan K, Subhasis R and Barindra K G 2016 Two new hexacoordinated coordination polymers of cadmium(II) containing bridging units only: Syntheses, structures and molecular properties J. Chem. Sci. 1281377

3. Hu Z B, Li B, Ju W Q, Liang Y N and Chen Z L 2016 Synthesis and structures of two new $\mathrm{Cu}(\mathrm{I})$ frameworks bearing1,3-bis(4-pyridyl)propane and inorganic linkers J. Chem. Sci. 128893

4. Ramachandra S, Schuermann K C, Edafe F, Belser P, Nijhuis C A, Reus W F, Whitesides G M and Cola L D 2011 Luminescent Ruthenium Tripod Complexes: Properties in Solution and on Conductive Surfaces Inorg. Chem. 501581

5. Guo Z G, Cao R, Wang X, Li H F, Yuan W B, Wang G J, Wu H H and Li J 2009 A Multifunctional 3D Ferroelectric and NLO-Active Porous Metal-Organic Framework J. Am. Chem. Soc. 1316894

6. Lo $\mathrm{K} \mathrm{K} \mathrm{W}$, Hui $\mathrm{W} \mathrm{K}$, Chung $\mathrm{C} \mathrm{K}$, Tsang $\mathrm{K} \mathrm{H} \mathrm{K}$, Lee T M, Li C K, Lau J S Y and Ng D C M 2006 Luminescent transition metal complex biotin conjugates Coordin. Chem. Rev. 2501724
7. He L H, Chen J L, Zhang F, Cao X F, Tan X Z, Chen X X, Rong G, Luo P and Wen H R 2012 Synthesis, characterization, and luminescence properties of mononuclear copper(I) halide complexes of 2-(2benzimidazolyl)-6-methylpyridine Inorg. Chem. Commun. 21125

8. Karreddula R, Akkili S and Katreddi H R 2016 Synthesis, X-ray crystal structure, DNA binding and Nuclease activity of lanthanide(III) complexes of 2-benzoylpyridine acetylhydrazone J. Chem. Sci. 1281265

9. Tarlok S L, Arvinder K, Rohit S, Madhu B, Amanpreet K J, Courtney E D and Jerry P J 2015 Synthesis, molecular structures and ESI-mass studies of copper(I) complexes with ligands incorporating $\mathrm{N}, \mathrm{S}$ and $\mathrm{P}$ donor atoms J. Chem. Sci. 1271859

10. Wei W, Wu M, Gao Q, Zhang Q, Huang Y, Jiang F and Hong M 2009 A Novel Supramolecular Tetrahedron Assembled from Tetranuclear Copper(I) Cluster Molecules via Aryl Embrace Interactions Inorg. Chem. 48420

11. Perruchas S, Goff X F L, Maron S, Maurin I, Guillen F, Garcia A, Gacoin T and Boilot J P 2010 Mechanochromic and Thermochromic Luminescence of a Copper Iodide Cluster J. Am. Chem. Soc. 13210967

12. Tsubomura T, Enoto S, Endo S, Tamane T, Matsumoto K and Tsukuda T 2005 Synthesis, Structure, Spectroscopic Properties, and Photochemistry of Homo- and Heteropolynuclear Copper(I) Complexes Bridged by the 2,5-Bis(2-pyridyl)pyrazine Ligand Inorg. Chem. 44 6373

13. Chen J L, Song P, Liao J S, Wen H R, Hong R J, Chen Z N and Chi Y 2010 Luminescent homodinuclear copper(I) halide complexes based on the 3,5-bis $\left\{6-\left(2,2^{\prime}-\right.\right.$ dipyridyl) \}pyrazole ligand Inorg. Chem. Commun. 13 1057

14. Jency $\mathrm{T}$ and Arunachalam R 2016 What Triggers Supramolecular Isomerism in Nonmolecular Solids? A case study of Copper Pyridazine Halides J. Chem. Sci. 1281687

15. Chen C, Ma J F, Liu B, Yang J and Liu Y Y 2011 Two Unusual 3D Copper(II) Coordination Polymers Constructed by p-Sulfonated Calixarenes and Bis(triazolyl) Ligands Cryst. Growth Des. 114491

16. Jin Q H, Hu K Y, Song L L, Wang R, Zhang C L, Zuo X and Lu X M 2010 Copper(II) complexes of chiral 1,2,3-triazole biheterocyclic 'click' ligands equipped in Cinchona alkaloid moiety Polyhedron 29441

17. Liao J H, Latouche C, Li B, Kahlal S, Saillard J Y and Liu C W 2014 A Twelve-Coordinated Iodide in a Cuboctahedral Silver(I) Skeleton Inorg. Chem. 532260

18. Hirtenlehner C and Monkowius U 2012 Syntheses, crystal structures and blue luminescence of $\mathrm{Cu}_{2} \mathrm{X}_{2}\left(\mathrm{Ph}_{3} \mathrm{P}\right)_{2}$ $[(-) \text {-nicotine }]_{2} \quad(\mathrm{X}=\mathrm{Br}, \mathrm{I})$ Inorg. Chem. Commun. 15109

19. Pachfule P, Dey C, Panda T, Vanka K and Banerjee R 2010 Structural Diversity in Partially Fluorinated Metal Organic Frameworks (F-MOFs) Composed of Divalent Transition Metals, 1,10-Phenanthroline, and Fluorinated Carboxylic Acid Cryst. Growth Des. 101351

20. Collas A, Bagrowska I, Aleksandrzak K, Zeller M and Blockhuys F 2011 Competition between MethoxyBased and Pyrazine-Based Synthons in MethoxySubstituted Distyrylpyrazines Cryst. Growth Des. 11 1299 
21. Xiao Y L, Jin Q H, Deng Y H, Li Z F, Yang W, Wu M H and Zhang C L 2012 Synthesis and structural characterization of five copper(I) complexes of [2,3f]-pyrazino-[1,10]phenanthroline-2,3-dicarbonitrile and triphenylphosphine Inorg. Chem. Commun. 15146

22. Park H, Krigsfeld G, Teat S J and Parise J B 2007 Synthesis and Structural Determination of Four Novel Metal-Organic Frameworks in a Zn-3-Amino-1,2,4Triazole System Cryst. Growth Des. 71343

23. Ouellette W, Prosvirin A V, Chieffo V, Dunbar K R, Hudson B and Zubieta J 2006 Solid-State Coordination Chemistry of the $\mathrm{Cu}$ /Triazolate/X System $\left(\mathrm{X}=\mathrm{F}^{-}, \mathrm{Cl}^{-}\right.$, $\mathrm{Br}^{-}, \mathrm{I}^{-}, \mathrm{OH}^{-}$and $\mathrm{SO}_{4}^{2-}$ ) Inorg. Chem. 459346

24. He X, Liu J J, Guo H M, Shao M and Li M X 2010 Syntheses, topological networks and properties of four complexes based on 4-amino-3,5-bis(3-pyridyl)-1,2,4triazole ligand Polyhedron 291062

25. He J, Zhang J X, Tan G P, Yin Y G, Zhang D and Hu M H 2007 Second Ligand-Directed Assembly of Photoluminescent $\mathrm{Zn}$ (II) Coordination Frameworks Cryst. Growth Des. 71508

26. Du M, Jiang X J and Zhao X J 2006 Controllable Assembly of Metal-Directed Coordination Polymers under Diverse Conditions: A Case Study of the $\mathrm{M}^{\mathrm{II}}-\mathrm{H}_{3}$ tma/Bpt Mixed-Ligand System Inorg. Chem. 45 3998

27. Dong Y B, Wang H Y, Ma J P and Huang R Q 2005 Synthesis and Characterization of New Coordination Polymers Generated from Triazole-Containing Organic Ligands and Inorganic Ag(I) Salts Cryst. Growth Des. 5789

28. Li B Y, Peng Y, Li G H, Hua J, Yu Y, Jin D, Shi $\mathrm{Z}$ and Feng S H 2010 Design and Construction of Coordination Polymers by 4-Amino- 3,5-bis(n-pyridyl)1,2,4-triazole $(n=2,3,4)$ Isomers in a Copper(I) Halide System: Diverse Structures Tuned by Isomeric and Anion Effects Cryst. Growth Des. 102192

29. Liu J J, He X, Shao M and Li M X 2009 Syntheses and topological networks of two azide complexes based on 4-amino-3,5-bis(3-pyridyl)-1,2,4-triazole ligands Inorg. Chem. Commun. 12972

30. Wang H Y, Cheng J Y, Ma J P, Dong Y B and Huang R Q 2010 Synthesis and Characterization of New Coordination Polymers with Tunable Luminescent Properties Generated from Bent 1,2,4-Triazole-Bridged N,N'Dioxides and Ln(III) Salts Inorg. Chem. 492416

31. Cheng L, Zhang W X, Ye B H, Lin J B and Chen X M 2007 In Situ Solvothermal Generation of 1,2,4Triazolates and Related Compounds from Organonitrile and Hydrazine Hydrate: A Mechanism Study Inorg. Chem. 461135

32. SMART and SAINT 1997 Area Detector Software Package and SAX Area Detector Integration Program; Bruker Analytical X-Ray; Madison, WI, USA

33. Sheldrick G M 1996 In SADABS, Program for area detector adsorption correction (Germany: Institute for Inorganic Chemistry, University of Göttingen)

34. Sheldrick G M 1997 In SHELXL-97, Program for refinement of crystal structures (Germany: University of Göttingen)
35. Frisch M J et al. 2009 In Gaussian 09; Revision A. 02 (Wallingford, CT: Gaussian, Inc.)

36. Becke A D 1993 Density-functional thermochemistry. III. The role of exact exchange J. Chem. Phys. 985648

37. Lee C, Yang W and Parr R G 1998 Development of the Colle-Salvetti Correlation-Energy Formula into a Functional of the Electron density Phys. Rev. B 37785

38. Höllwarth A, Böhme M, Dapprich S, Ehlers A W, Gobbi A, Jonas V, Köhler K F, Stegmann R, Veldkamp A and Frenking G 1993 A set of d-polarization functions for pseudo-potential basis sets of the main group elements $\mathrm{Al} \mathrm{Bi}$ and f-type polarization functions for $\mathrm{Zn}, \mathrm{Cd}, \mathrm{Hg}$ Chem. Phys. Lett. 208237

39. Guo H M, He X, Liu J J, Han J and Li M X 2011 Syntheses, structures and properties of five copper coordination polymers constructed by the triazole ligand Polyhedron 301982

40. Li M X, Wang H, Liang S W, Shao M, He X, Wang Z X and Zhu S R 2009 Solvothermal Synthesis and Diverse Coordinate Structures of a Series of Luminescent Copper(I) Thiocyanate Coordination Polymers Based on N-Heterocyclic Ligands Cryst. Growth Des. 94626

41. Harris D C and Bertolucci M D 1978 In Symmetry and Spectroscopy: An Introduction to Vibrational and Electronic Spectroscopy (New York: Oxford University Press)

42. Mi B X, Wang P F, Gao Z Q, Lee C S, Lee S T, Hong $\mathrm{H} \mathrm{L}$, Chen X M, Wong M S, Xia P F, Cheah K W, Chen C H and Huang W 2009 Strong Luminescent Iridium Complexes with $\mathrm{C}^{\wedge} \mathrm{N}-\mathrm{N}$ Structure in Ligands and Their Potential in Efficient and Thermally Stable Phosphorescent OLEDs Adv. Mater. 14339

43. Zhang G Y, Gao D Z, Zhang X and Sun Y Q 2011 Silver(I) Complexes with Dithioether Ligands: Syntheses, Crystal Structures, and Fluorescence Properties $Z$. Anorg. Allg. Chem. 6371383

44. Dong Y B, Wang P, Ma J P, Zhao X X, Wang H Y, Tang B and Huang R Q 2007 Coordination-Driven Nanosized Lanthanide "Molecular Lantern" with Tunable Luminescent Properties J. Am. Chem. Soc. 1294872

45. Du M, Zhang Z H, You Y P and Zhao X J 2008 RIsophthalate $\left(\mathrm{R}=-\mathrm{H},-\mathrm{NO}_{2}\right.$, and $\left.-\mathrm{COOH}\right)$ as modular building blocks for mixed-ligand coordination polymers incorporated with a versatile connector 4-amino-3,5bis(3-pyridyl)-1,2,4-triazole CrystEngComm 10306

46. Liang S W, Li M X, Shao M and Miao Z X 2006 Hydrothermal synthesis and crystal structure of a novel cyanide-bridged double helical copper(I) coordination polymer $\left[\mathrm{Cu}_{3}(\mathrm{CN})_{3}(\text { phen })\right]_{n}$ Inorg. Chem. Commun. 91312

47. Merrill D, Harrington J M, Lee H S and Hancock R D 2011 Unusual Metal Ion Selectivities of the Highly Preorganized Tetradentrate Ligand 1,10-Phenanthroline2,9-dicarboxamide: A Thermodynamic and Fluorescence Study Inorg. Chem. $\mathbf{5 0} 8348$

48. Hu X, Guo J X, Liu C, Zen H, Wang Y J and Du W J 2009 Two new supermolecular structures of organic-inorganic hybrid compounds: $\left[\mathrm{Zn}(\right.$ phen $)\left(\mathrm{SO}_{4}\right)$ $\left.\left(\mathrm{H}_{2} \mathrm{O}\right)_{2}\right]_{\mathrm{n}}$ and $\left[\mathrm{Cu}(\right.$ phen $\left.)\left(\mathrm{H}_{2} \mathrm{O}\right)_{2}\right] \cdot \mathrm{SO}_{4}$ (phen $=1,10-$ phenanthroline) Inorg. Chim. Acta 3623421 